\title{
Assessment of Group B Streptococcal Opsonins in Human and Rabbit Serum by Neutrophil Chemiluminescence
}

\author{
Val G. Hemming, Robert T. Hall, Philip G. Rhodes, Ann O. Shigeoka, \\ and HARRY R. HILL \\ From the Division of Clinical Immunology, the Department of Pediatrics and the Department of \\ Pathology, University of Utah College of Medicine, Salt Lake City, Utah 84132 and the Children's \\ Mercy Hospital, University of Missouri, Kansas City, Missouri 64108
}

\begin{abstract}
A B S T R A C T The factors important in host defense against group B streptococci are not well understood. The role of antibody and complement in the prevention of serious infection by these organisms is not known because, to date, a reliable measure of functional opsonic activity has not been developed. Recently, it has been shown that neutrophils produce a chemiluminescence after ingestion of particulate matter, and that this event can be detected and quantitated in a liquid scintillation system. We have adapted the chemiluminescence procedure to examine rabbit hyperimmune and human serum for the presence of group B streptococcal opsonins. Group B streptococci of types Ia, II, and III that were opsonized in homologous but not heterologous type serum produced a peak in chemiluminescence when added to normal human neutrophils. Such activity was correlated, in each instance, with ingestion of bacteria by neutrophils and deposition of immunoglobulin and C3 on the bacterial surface as detected by indirect immunofluorescence.

With this assay, we have examined sera from colonized and diseased patients for the presence of opsonins to types Ia, II, and III group B streptococci. Maternal sera often contained type-specific opsonins which resided in the IgG fraction and which crossed the placenta to appear in paired cord specimens. $63 \%$ of patients colonized with group B streptococci had serum opsonins to their colonizing type of organism. In contrast, none of the 15 patients with sepsis or meningitis had opsonins directed against their infecting strain. These data suggest that the
\end{abstract}

This work was presented, in part, at the Annual Meeting of the Society for Pediatric Research, St. Louis, Mo., 29 April 1976.

Dr. Hill is an Investigator of the Howard Hughes Medical Institute.

Received for publication 24 March 1976 and in revised form 30 August 1976.

The Journal of Clinical Investigation

Volume 58 lack of type-specific opsonins to group B streptococci may be one of the important factors in determining host susceptibility to systemic infection with strains of this group.

\section{INTRODUCTION}

In recent years streptococci of Lancefield's group B have become a leading cause of serious infections in infancy. Although a number of clinical and epidemiological reports on infection due to these organisms have appeared in the literature (1-8), there is little definitive information on the factors important in the host defense mechanism against the strains of this group. Lancefield and co-workers have shown that rabbit hyperimmune group B streptococcal antiserum will passively protect mice injected with virulent strains of group B streptococci (9-10). Since such antiserum does not appear to possess direct bactericidal activity, mouse protection most likely results from opsonic antibodies present in the serum. The role of specific and nonspecific opsonins in the prevention of infection due to group B streptococci has not been adequately investigated, however, because of the lack of a reliable method for detecting and quantitating functional opsonins for these organisms.

Allen and associates (11-15) have reported that human neutrophils emit a chemiluminescence after phagocytosis of opsonized bacteria. The chemiluminescence, which can be detected and quantitated in a liquid scintillation counter, appears to result from decay to the ground state of electronically excited carbonyl groups thought to be generated during singlet oxygen mediated oxidation of phagocytized substrate. In the studies reported here, we have adapted the chemiluminescence procedure to examine rabbit hyperimmune and human serum for the presence of group B streptococcal opsonins. In 
addition, we used this technique to assess opsonic activity in serum from patients with group B streptococcal disease as well as colonized and uncolonized individuals in an attempt to define what role functional opsonic antibodies have in preventing clinical infection due to streptococci of Lancefield's group B.

\section{METHODS}

Preparation of organisms. Reference strains of group B streptococci type Ia (090), II (18RS21), and III (D136C) (kindly supplied by Dr. Rebecca C. Lancefield of the Rockefeller University, New York) or group B streptococcal strains isolated from infected or colonized patients (wild strains) were cultured at $37^{\circ} \mathrm{C}$ in $50 \mathrm{ml}$ of Todd-Hewitt (Difco Laboratories, Detroit, Mich.) broth for $20 \mathrm{~h}$. In selected experiments, the strains were grown in the buffered, glucose-enriched broth described by Baker et al. (16), and harvesting was carried out after $4 \mathrm{~h}$ of incubation during log phase growth. The organisms in the broth cultures were sedimented by centrifugation, the supernatant broth was removed and discarded, and the concentrated organisms were washed three times in sterile phosphate-buffered saline $(\mathrm{PBS})^{1}\left(4,500 \mathrm{ml}\right.$ distilled water, $5.2 \mathrm{~g} \mathrm{Na}_{2} \mathrm{HPO}_{4}, 0.9 \mathrm{~g} \mathrm{KCl}$, $\left.0.9 \mathrm{~g} \mathrm{KH}_{2} \mathrm{PO}_{4}, 36 \mathrm{~g} \mathrm{NaCl}\right)$. Standard suspensions of organisms of each reference type were prepared by diluting the concentrated, washed organisms in sterile PBS to an optical density (OD) of 0.9 at a wave length of $620 \mathrm{~nm}$ (Spectronic 20 , Bausch \& Lomb Inc., Rochester, N. Y.). These standard suspensions contained from $5.0 \times 10^{8}$ to $1.0 \times 10^{9}$ colonyforming $\mathrm{U} / \mathrm{ml}$.

Opsonization procedure. Strains of group B streptococci (types Ia, II, and III) were opsonized by mixing $0.5 \mathrm{ml}$ of the standard solution (OD 0.9 at $620 \mathrm{~nm}$ ) with $0.1 \mathrm{ml}$ of the test serum (1:6 dilution) in a $12 \times 75 \mathrm{~mm}$ sterile capped tube (Falcon Plastics, Div. of BioQuest, Oxnard, Calif.). In selected experiments with rabbit hyperimmune serum and in most of the studies with human serum, $0.025 \mathrm{ml}$ of whole human complement (Cordis Laboratories, Miami, Fla.) was added to the reaction mixture. This volume of the preparation was found to maximally enhance the effect of heated rabbit or human serum. Addition of a larger volume had no more effect than $0.025 \mathrm{ml}$. The phagocytic mixture was then rotated for $30 \mathrm{~min}$ at $37^{\circ} \mathrm{C}$. After rotation, each tube was centrifuged. The cell button was washed twice in PBS, then resuspended to its original volume $(0.5 \mathrm{ml})$ in PBS.

Preparation of polymorphonuclear leukocytes. Human polymorphonuclear leukocyte (PMN) suspensions were prepared from fresh samples of heparinized $(10 \mathrm{U} / \mathrm{ml})$ whole blood obtained from healthy adult volunteers. After sedimentation of the erythrocytes, the leukocyte-rich plasma was removed, centrifuged, and the leukocyte button was washed twice in PBS. The washed leukocytes were suspended in PBS to a concentration of $1.0 \times 10^{7} \mathrm{PMNs} / \mathrm{ml}$.

Preparation of precipitin antigen. Hot $\mathrm{HCl}$ and TCA extracts of the reference strains of group B streptococci were prepared by slight modifications of the procedures of Lancefield and Freimer $(9,17,18)$.

Scintillation counting. Beckman Poly Q (Beckman Instruments, Inc., Fullerton, Calif.) vials were wrapped in aluminum foil and stored in darkness for at least $18 \mathrm{~h}$ before use. Scintillation counting was performed in ambient light and

\footnotetext{
${ }^{1}$ Abbreviations used in this paper: $\mathrm{CL}$, chemiluminescence; PBS, phosphate-buffered saline; PMN, polymorphonuclear leukocyte.
}

temperature in a Beckman LS 100c liquid scintillation system (Beckman Instruments, Inc.) out of phase, with one photo multiplier tube disconnected. $0.5-\mathrm{ml}$ aliquots of the PMNs and $0.5 \mathrm{ml}$ of the bacterial suspensions were mixed and the volume adjusted to $3.5 \mathrm{ml}$ with sterile PBS. The vial was capped, mixed well, placed in the scintillation counter, and counted for $1 \mathrm{~min}$ at approximately $10-\mathrm{min}$ intervals for a total of $100 \mathrm{~min}$. The chemiluminescence detected by the counter is expressed in counts per minute.

Visual microscopic examination of reaction mixtures. After scintillation counting, each reaction mixture was centrifuged at $5,000 \mathrm{rpm}$ for $5 \mathrm{~min}$, the supernate was removed, and the cell button was resuspended in a small volume of PBS. An aliquot of this mixture was placed on a clean microscope slide and air dried. The slides were fixed for $10 \mathrm{~min}$ in $100 \%$ methanol and stained with Giemsa (Harleco, Gibbstown, N. J., 1:50 in distilled water) for $1 \mathrm{~h}$. Each slide was examined microscopically under oil immersion to visually access phagocytosis of the organisms. We found that attempting to quantitate the degree of phagocytosis visually by counting the percentage of PMNs ingesting or the number of bacteria ingested per PMN was extremely difficult. On the other hand, there was a clearly visable distinction between the appearance of preparations in which there had been phagocytosis and those in which no ingestion had occurred. In positive smears, the majority of the organisms appeared to be intracellular and almost all PMNs had numerous ingested bacteria. In contrast negative preparations contained bacteria which were predominantly unassociated with $\mathrm{PMNs}$ and only an occasional leukocyte contained organisms. All slides were interpreted without the knowledge of what made up the phagocytic mixture. Moreover, there was excellent correlation in interpreting phagocytosis vs. no phagocytosis by three individual observers.

Preparation of rabbit antiserum. Rabbit hyperimmune serum was prepared by the method of Lancefield with formalinized whole cell vaccines (17). Additional reference antiserum (Ia, II, and III) was kindly supplied by Dr. Lancefield and by Dr. R. R. Facklam and Dr. H. Wilkinson of the Center for Disease Control, Atlanta, Ga. Group B streptococcal grouping antiserum was obtained from Burroughs Wellcome Co., (Research Triangle Park, N. C.). This latter antiserum gives excellent capillary precipitin reactions with group B streptococcal extracts and forms heavy precipitin lines with group B culture filtrates in counterimmunoelectrophoresis (19).

Immunofluorescence procedure. Fluorescein isothiocyanate conjugated antirabbit globulin (Behring Diagnostics, American Hoechst Corp., Somerville, N. J.) or antihuman C.3 antiserum (Behring Diagnostics) $(0.1 \mathrm{ml}$ of a $1: 3$ dilution) was added to the cell buttons of opsonized or unopsonized bacteria. Each tube was mixed, incubated on ice for $30 \mathrm{~min}$ and then washed three times with PBS. After washing, $0.1 \mathrm{ml}$ of a 1:2 mixture of normal saline and glycerine was added to the bacterial button and the tube was mixed. One drop of the mixture was placed on a clean microscope slide, a cover glass was placed over the drop, and the mixture was examined immediately with a Zeiss ultraviolet microscope using an epi-illuminator (Carl Zeiss, Inc., New York). The amount of fluorescence observed on the surface of the bacteria was graded from trace (small) amount of fluorescence to $4+$ (heavy fluorescence).

Agglutination procedure. Rabbit antisera were tested for the presence of type-specific agglutinins by mixing a drop of the bacterial cell suspension with a drop of the test serum in a sterile glass test tube. These preparations were examined for the presence of agglutination of the organisms on an inverted microscope. 
Capillary precipitin procedure. Capillary precipitin tests were done by mixing equal volumes of the antiserum and antigen to be tested in sterile capillary tubes $(1.2 \mathrm{~mm}$ inside diameter) (17). Typing reactions were read in 5-10 min; the formation of a precipitate was interpreted as a positive precipitin test.

Clinical specimens. Serum specimens were obtained from 50 adults and 47 infants. Included in these sera were samples from 18 colonized mothers, 9 colonized infants, 19 septic infants and their mothers, 2 infected adults, and 11 normal maternal cord pairs. The colonization status was determined from throat, ear, umbilical, blood, or cerebrospinal fluid cultures in the colonized or diseased infants. The mothers of these patients had vaginal, cervical, and throat cultures taken. All swabs were plated onto $5 \%$ sheep blood agar plates without the addition of selective antibiotics. After incubation for 18-24 h, typical streptococcal colonies were identified; all strains were grouped and typed by Dr. Lancefield's capillary precipitin technique (17) and by counterimmunoelectrophoresis (19). The colonization status of the maternal-cord infants pairs was not determined. Sera were frozen at $-20^{\circ}$ to $-70^{\circ} \mathrm{C}$ and thawed only once before testing. All sera were tested in the presence of a maximally enhancing amount of whole human complement.

\section{RESULTS}

Chemiluminescence (CL). The addition of stock strains of group B streptococci, pre-opsonized in homologous type rabbit antiserum, to washed human leukocytes resulted in an increase in CL which was easily measured in the scintillation counter (Fig. 1). No increase in CL was noted when unopsonized bacteria were utilized. A small CL peak was noted for type II, whereas higher peaks were seen for types Ia and III. The rabbit antisera used in this experiment were free of complement (no change in the CL elicited after heating at $56^{\circ} \mathrm{C}$ for $1 \mathrm{~h}$ ). Addition of whole human complement to the pre-opsonization mixtures accentuated the CL peak for type Ia by $3,500 \mathrm{cpm}$ and for type II by $6,500 \mathrm{cpm}$. The peak for type III was not increased by the addition of complement.

A recently isolated type III (wild) strain from an infant with group B streptococcal sepsis was next examined to determine the effect of complement on its opsonization. The peak in CL observed when this organism was opsonized in heated type III rabbit antiserum $\left(14.8 \times 10^{3} \mathrm{cpm}\right)$ was not significantly different from that obtained with the same serum and added complement $\left(14.7 \times 10^{3} \mathrm{cpm}\right)$. Moreover, the CL curves observed with the two phagocytic mixtures were essentially identical. No CL peak was noted when either stock or wild strains of group B streptococci were opsonized in the complement preparations alone.

Additional studies were carried out to determine the effects on CL of $(a)$ using buffered, enriched broth which has been reported to enhance group B capsular polysaccharide production (16), (b) using $\log$ phase growth organisms rather than 20 -h cultures,

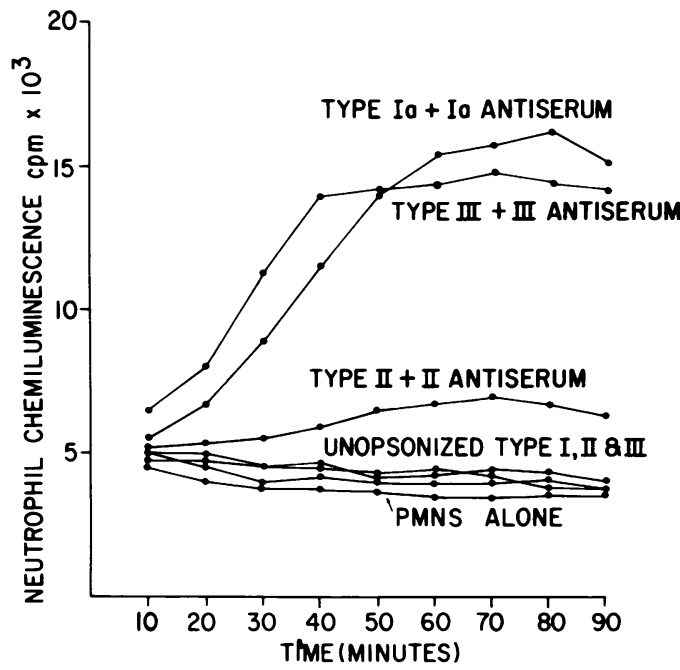

FIGURE 1 Neutrophil chemiluminescence elicited over a 90min period by stock group B streptococcal strains of types Ia, II, and III which were opsonized in complement-free homologous type rabbit hyperimmune serum. The controls in this experiment are PMNs plus unopsonized bacteria, or the PMN mixture without bacteria.

and $(c)$ varying the number of organisms presented to the cells.

The use of organisms grown in the buffered, enriched broth resulted in a higher rather than a lower peak in CL. The peak in CL produced by type III strains grown in this medium and opsonized in homologous type rabbit or human serum was increased by approximately 4,000 cpm (35-50\%) over that produced by strains grown in regular Todd-Hewitt broth and opsonized in the same sera. Addition to PMNs of unopsonized bacteria grown in the enriched broth or of such organisms treated with serum lacking type specific antibody did not result in a peak in CL. Moreover, the use of organisms in log phase growth (4 $\mathrm{h}$ incubation), which should presumably have more antiphagocytic factors, did not result in a decrease in the CL peak. Wild type III streptococci in log phase growth opsonized in type III rabbit antiserum and complement produced a slightly higher peak in CL $\left(17.5 \times 10^{3} \mathrm{cpm}\right)$ than did 20 -h cultures opsonized in the same opsonic mixture $\left(16.0 \times 10^{3} \mathrm{cpm}\right)$.

The number of organisms presented to the PMNs had a significant effect on the resulting CL. Very low, almost undetectable peaks were obtained with lower numbers of bacteria ( 2 logs below the usual number of $5 \times 10^{8}$ to $\left.1 \times 10^{9}\right)$. In contrast, a 3-fold higher number of organisms increase the peak in CL by an average of $133 \%$; 5 -fold higher by $315 \%$; and 10 -fold by $333 \%$. The number $5 \times 10^{8}$ to $1 \times 10^{9}$ organism (OD 0.9 at $620 \mathrm{~nm}$ ) was selected (somewhat arbitrarily) as a convenient one that produced a significant but not maximum CL response. With these conditions the 


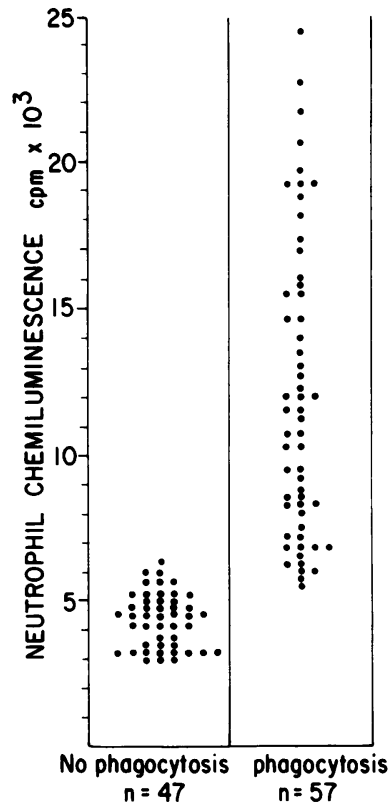

FIGURE 2 Peak neutrophil chemiluminescence elicited by group B streptococci correlated with the presence or absence of phagocytosis as determined by microscopic examination of each of 104 neutrophil-bacteria reaction mixtures.

standard deviation of triplicate sampling averaged $5 \%$ of the mean (five separate experiments) while the same opsonizing serum tested on three different occasions had mean peaks in CL with a standard deviation that averaged $7 \pm 6 \%$ of the mean (mean variance $6 \pm 6 \%$ of the mean).

The data depicted in Fig. 2 are the results of 104 separate observations of the bacteria-neutrophil preparations plotted by the peak in CL and the presence or absence of bacteria inside neutrophils as determined by microscope examination. In every case, where the CL peak exceeded $6,500 \mathrm{cpm}$, the smear showed that the majority of the bacteria were intracellular and that most PMNs had phagocytized. Conversely, phagocytosis was not observed in any of the preparations which had a CL peak of less than $5,500 \mathrm{cpm}$. There were 12 instances, $11 \%$, in which one could not predict whether phagocytosis had taken place by referring to the CL peak alone. These mixtures had CL peaks between 5,500 and 6,500 cpm and showed only minimal phagocytic uptake. This led us to select $6,500 \mathrm{cpm}$ as the level of CL which indicates the presence of functional opsonic antibodies.

Cross-opsonization and absorption studies. To determine if the group B streptococcal opsonic antibodies measured by the CL procedure were type specific the following experiments were performed: (a) group B streptococci were pre-opsonized with heterologous type rabbit antiserum and tested for their ability to elicit a peak in $\mathrm{CL} ;(b)$ an aliquot of each type of rabbit antiserum was absorbed with an equal volume of live homologous or heterologous type organisms; these absorbed sera were then used to pre-opsonize type Ia, II, and III organisms; (c) an aliquot of each type of rabbit antiserum was absorbed with an equal volume of homologous type $\mathrm{HCl}$ or TCA extracted antigen. The resulting precipitate was removed by centrifugation and this absorbed serum wass used to pre-opsonize both homologous and heterologous type organisms.

The results of several of these experiments are summarized in Table I. CL peaks were observed for each of the three streptococcal types opsonized with homologous type rabbit antiserum. Absorption of the three types of rabbit serum with homologous type $\mathrm{HCl}$ or TCA extracts had varying effects on the opsonic activity as measured by $\mathrm{CL}$. Both $\mathrm{HCl}$ and TCA extracts reduced the CL activity of the type Ia serum. In contrast, absorption of type II serum with either of these extracts markedly enhanced its CL activity. The opsonic activity of the type III serum was unchanged when absorbed with $\mathrm{HCl}$-extracted antigen, but was somewhat reduced when absorbed with TCA extract. In no instance did homologous absorption with either the $\mathrm{HCl}$ or TCA extract completely remove the opsonic activity of any of the

TABLE I

Effect of Homologous and Heterologous Type Absorption of Group B Streptococcal Antiserum on Opsonization of Homologous Type Group B Streptococci as Measured by Chemiluminescence

\begin{tabular}{clc}
\hline Antiserum & Absorption* & Peak in CL \\
\hline & & $c p m \times 10^{3}$ \\
Ia & None & 16.4 \\
Ia & HCl Ia & 7.7 \\
Ia & TCA Ia & 8.0 \\
Ia & Ia cells & 4.3 \\
Ia & II cells & 15.9 \\
Ia & III cells & 16.0 \\
II & None & 6.0 \\
II & HCl II & 23.9 \\
II & TCA II & 16.3 \\
II & II Cells & 3.9 \\
II & Ia cells & 5.9 \\
II & III cells & 6.2 \\
III & None & 13.4 \\
III & HCl III & 13.1 \\
III & TCA III & 9.8 \\
III & III cells & 3.8 \\
III & Ia cells & 13.0 \\
III & II cells & 12.8 \\
\end{tabular}

* Concentrated, live whole group B streptococcal cells, hot $\mathrm{HCl}$, or TCA extracts of group B streptococcal cells. 
sera tested. This absorption did, however, remove all detectable precipitins. Absorption of each serum with an equal volume of whole, homologous type organisms removed all opsonic activity from that aliquot of serum. However, absorption of serum with heterologous concentrated organisms did not decrease the serum's opsonic activity against the homologous strain. Type-specific agglutinins were present in all three types of rabbit antiserum. Absorption with homologous type $\mathrm{HCl}$ and(or) TCA antigens removed these agglutinins from types Ia and III antisera, but not from type II.

Experiments were conducted to see if antibodies to the group B streptococcal group-specific substance were opsonically active in this system. Pre-opsonization of each of the reference strains with group B streptococcal grouping serum with and without the addition of human complement failed to elicit a CL peak or visual evidence of phagocytosis in these experiments.

$C L$ assay of human serum. The CL opsonic assay for group B streptococci has also been used to measure opsonins in human serum. A representative experiment is shown in Fig. 3. Fresh human serum from a single donor (V. G. H.) was found to contain opsonins for types II and III streptococci, but no opsonic activity for type Ia. The opsonins against types II and III were removed by homologous but not heterologous type absorption with whole group B streptococcal cells (Table II). Furthermore, the serum could be titered by twofold dilutions. (CL peak greater than $6,500 \mathrm{cpm}$ : type II-1:64, type III-1:32).

Indirect immunofluorescence studies. Group B streptococci of types Ia, II, and III were preopsonized in homologous and heterologous type rabbit antiserum. These preparations were then incubated with antirabbit globulin (goat) conjugated with fluorescein isothiocyanate. Organisms pre-opsonized in homologous type antiserum gave strong fluorescent reactions while those pre-opsonized in heterologous

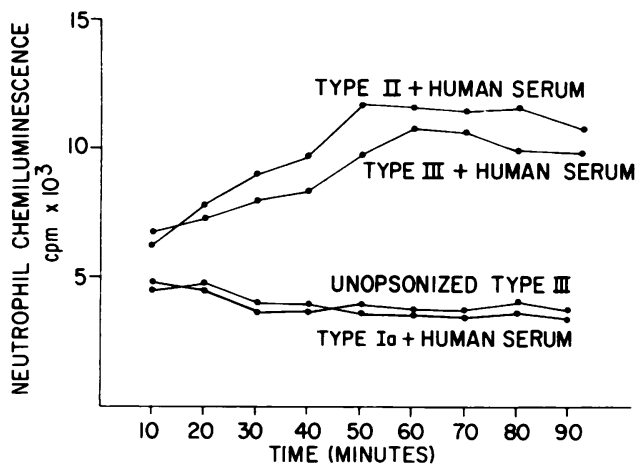

FIGURE 3 Neutrophil chemiluminescence elicited by group B streptococci of types Ia, II, and III opsonized in fresh adult human serum (V. G. H.). Unopsonized type III organisms were used as controls.
TABLE II

Effect of Homologous and Heterologous Type Absorption on Group B Streptococcal Opsonins in Human Serum

\begin{tabular}{cccccc}
\hline & & \multicolumn{3}{c}{$\begin{array}{c}\text { Peak in CL } \\
\text { produced by group B } \\
\text { streptonccal types }\end{array}$} \\
\cline { 3 - 6 } Opsonizing serum & $\begin{array}{c}\text { Absorbed } \\
\text { with* }\end{array}$ & Ia & II & III \\
\hline \multirow{2}{*}{ Human adult (V. G. H.) } & Nothing & 4.8 & 11.6 & 10.8 \\
& Ia cells & 4.3 & 10.7 & 11.0 \\
& II cells & 4.4 & 3.9 & 10.6 \\
& III cells & 4.4 & 10.1 & 4.3
\end{tabular}

* Absorbed with an equal volume of packed live organisms at $37^{\circ} \mathrm{C}$ for $30 \mathrm{~min}$.

type serum showed little or no fluorescence. Similar results were obtained when organisms preopsonized in human (V. G. H.) serum were examined. Reference organisms (Ia, II, and III) were pre-opsonized, then incubated with rabbit antihuman IgG, IgA, IgM, and anti-C3. No indirect immunofluorescence was observed in the anti-IgM or anti-IgA preparations. However, organisms of types II and III showed $4+$ immunofluorescence when incubated with antiIgG. Pre-opsonized Ia organisms, which did not elicit a peak in CL, showed only trace amounts of fluorescence with the fluorescein-conjugated anti-IgG. Each of the three streptococcal types opsonized in the fresh human serum had C3 on their surface as determined by indirect immunofluorescence. The amount of C3 on the surface of the Ia organisms, which showed no fluorescence with anti-IgG and which failed to produce a CL peak, was not markedly different from that on the surface of the type II and III strains $(3+$ to $4+)$.

Prevalence of group B streptococcal opsonins in human sera. 11 maternal-cord paired sera were collected and examined by the CL assay for opsonins against the Ia, II, and III reference strains of group B streptococci. The colonization status of these individuals, unfortunately, was not known. As shown in Fig. 4, none of the maternal-infant sera had significant opsonic activity $(\geq 6,500 \mathrm{cpm})$ against Ia organisms and only $18 \%$ of the infants and $27 \%$ of the mothers had serum opsonins to type II. In contrast, $73 \%$ of the cord sera and $82 \%$ of the maternal specimens possessed opsonic activity to group B streptococci of type III. When present, opsonic activity was usually slightly higher in the maternal serum than in the corresponding cord specimen. Indirect immunofluorescent studies showed significant $\left(3^{+}\right.$or greater) deposition of IgG and C3 on the surface of bacteria incubated with maternal and cord specimens possessing opsonic activity. No IgA or IgM could be detected. 

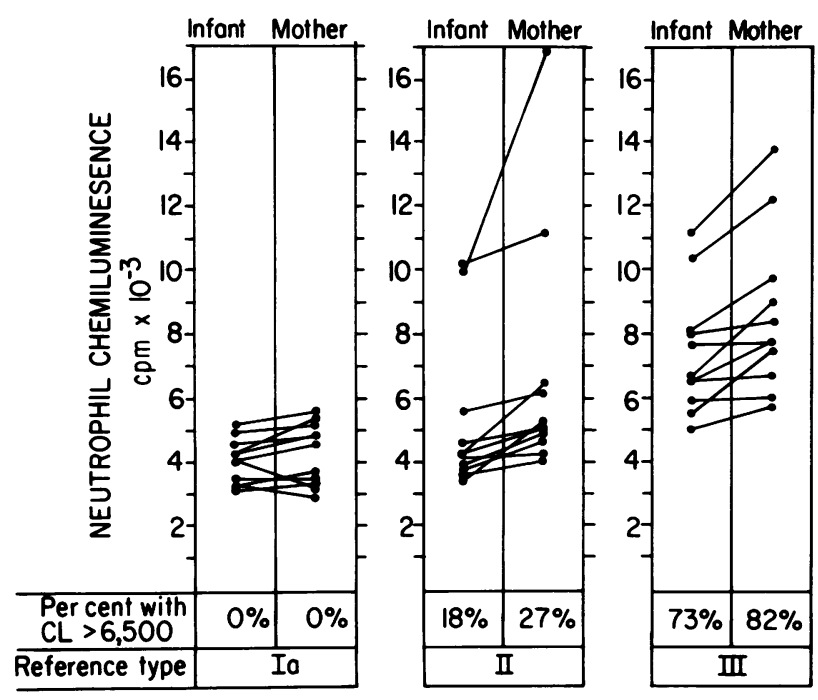

FIGURE 4 Opsonins to group B streptococci in paired maternal and cord sera as measured by the CL assay. (Phagocytic uptake associated with CL peak of $\geq 6,500 \mathrm{cpm}$ ).

In sera lacking opsonic activity only trace amounts of IgG and C3 were found on the bacterial surface by indirect immunofluorescence.

A total of 50 adult sera and 47 infant or cord sera have been examined for opsonic activity to types Ia, II, and III group B streptococcal reference strains. These specimens include ones from the diseased and colonized infants and their mothers, whose colonization status is known, the maternal cord pairs just discussed, and several adult volunteers who were not colonized. The sera were examined with the addition of whole human complement. $74 \%$ of adults and $58 \%$ of infants were found to have opsonic activity for type III group B streptococci, while opsonins to type II were present in $40 \%$ of the adult and $28 \%$ of the infant sera. Only $12 \%$ of the adult and $13 \%$ of the infant sera contained opsonic activity for type Ia strains.

Included in the 97 sera examined thus far are 67 specimens from patients with group B streptococcal disease or ones colonized with strains of this group. $62 \%$ of the patients were colonized or had disease due to type II strains, $25 \%$ with type III, and $13 \%$ with type Ia strains. The clinical data from the 19 diseased infants and two diseased adults are shown in Table III. 18 of the infants had blood cultures positive for group B streptococci within $48 \mathrm{~h}$ of birth. Six of the patients also had roentgenographic or autopsy evidence of pneumonia. Only one of these early onset cases had meningitis. The infant who had late onset disease (10 days) had meningitis with positive cerebrospinal fluid cultures for type III group B streptococci. The two adults include a 22-yr-old female with puerperal sepsis (type II) who survived and an 80-yr-old female who developed fatal group B streptococcal sepsis and meningitis (type III).

All sera were tested against the homologous type reference strain, and when available against the infecting or colonizing strain isolated from the patient. (Unfortunately, some of these organisms were lost before initiation of these antibody studies.)

$56 \%$ of sera from the 18 colonized mothers (whose infants did not become ill) contained opsonins to the homologous type reference strain (Table IV). Nine infants from these 18 colonized mothers were also colonized. Unfortunately, the organisms isolated from only four of these maternal infant pairs were available for testing. Two of the pairs (50\%) contained high levels of opsonins to the offending organism. Seven of the nine colonized infants $(78 \%)$ had serum opsonins to the homologous type reference strain. In contrast none of the 13 septicemic infants or the 2 septicemic adults from whom organisms were available had serum opsonic activity ( $C L \geq 6,500)$ to their infecting organism (Tables III and IV). 3 of the 19 diseased infants and one diseased adult did have antibody to the homologous type reference strain. The differences in antibody prevalence between the colonized and diseased patients against their own strain $(P \leq 0.023)$ or the homologous type reference strain $(P \leq 0.005)$ was significant by the Fischer Exact test.

\section{DISCUSSION}

Type-specific opsonins for group B streptococci have been demonstrated in human adult and newborn infant serum. Maternal opsonic antibody, which appears to reside in the IgG fraction (as determined by indirect immunofluorescence), crosses the placenta and appears in the newborn infant in most instances. Opsonins to type III group B streptococci were present in one-half to three-fourths of sera tested while antibodies to type II and Ia were less common. Opsonins directed toward the colonizing strain or a homologous type reference strain of group B streptococci were often present in the serum of asymptomatic, colonized patients. In contrast, none of 15 diseased patients had serum opsonic activity for their infecting strain and only 4 of $21(19 \%)$ had opsonins to the homologous type reference strain. These data suggest that the lack of type-specific serum opsonins for group B streptococci may be a factor in the development of serious infection with these organisms.

The antigenic determinants responsible for virulence and the production of opsonic antibodies for the different types of group B streptococci are not precisely defined. The type I strains (Ia, Ib, and Ic) have several known detectable antigens which include the following: (a) Ia and Ic have a shared, major 
TABLE III

Clinical and Bacteriologic Data and Serum Opsonic Activity in Patients with Systemic Group B Streptococcal Disease

\begin{tabular}{|c|c|c|c|c|c|c|c|}
\hline \multirow[b]{2}{*}{ Subject } & \multirow[b]{2}{*}{ Weight } & \multirow[b]{2}{*}{$\begin{array}{c}\text { Age at } \\
\text { diagnosis }\end{array}$} & \multirow[b]{2}{*}{ Diagnosis } & \multirow[b]{2}{*}{ Outcome! } & \multirow[b]{2}{*}{$\begin{array}{c}\text { Type } \\
\text { recovered }\end{array}$} & \multicolumn{2}{|c|}{$\begin{array}{l}\text { Serum opsonic activity } \\
\text { (CL peak) of the patient's } \\
\text { serum against }\end{array}$} \\
\hline & & & & & & $\begin{array}{l}\text { Infecting } \\
\text { strain }\end{array}$ & $\begin{array}{l}\text { Homologous type } \\
\text { reference strain }\end{array}$ \\
\hline & g & & & & & \multicolumn{2}{|c|}{$c p m \times 10^{3}$} \\
\hline 1 & 1,200 & NB* & Pneumonia and sepsis & $\mathbf{D}$ & II & $6.4(60)$ & $5.1(60)$ \\
\hline 2 & 3,000 & NB & Sepsis & $\mathbf{S}$ & II & $5.1(75)$ & $5.1(60)$ \\
\hline 3 & 2,900 & NB & Sepsis & D & II & $4.7(60)$ & $5.9(75)$ \\
\hline 4 & 2,800 & NB & Pneumonia, sepsis & D & II & $6.2(56)$ & $7.5(68)$ \\
\hline 5 & 3,700 & NB & Sepsis & D & II & $6.1(60)$ & $6.4(75)$ \\
\hline 6 & 2,540 & NB & Sepsis & $\mathbf{S}$ & III & $5.2(60)$ & $6.2(60)$ \\
\hline 7 & 3,400 & NB & Sepsis and pneumonia & D & II & $3.4(56)$ & $3.9(56)$ \\
\hline 8 & 2,650 & NB & Sepsis, meningitis pyarthrosis & $\mathbf{S}$ & Ia & $4.9(75)$ & $9.3(70)$ \\
\hline 9 & 2,230 & NB & Sepsis & $\mathbf{S}$ & II & $6.1(56)$ & $6.3(56)$ \\
\hline 10 & 3,070 & NB & Sepsis, pneumonia & D & II & $6.2(60)$ & $6.0(45)$ \\
\hline 11 & 2,060 & NB & Pneumonia, sepsis & $\mathbf{S}$ & II & $5.4(45)$ & $7.0(60)$ \\
\hline 12 & 2,630 & NB & Sepsis & $\mathbf{S}$ & III & - & $4.5(60)$ \\
\hline 13 & 1,600 & NB & Sepsis & D & II & - & $4.1(60)$ \\
\hline 14 & 1,750 & NB & Pneumonia, sepsis & $\mathbf{S}$ & III & - & $9.2(75)$ \\
\hline 15 & 2,600 & NB & Sepsis & S & II & - & $4.3(72)$ \\
\hline 16 & 3,100 & NB & Sepsis & $\mathbf{S}$ & II & $3.9(60)$ & $5.9(75)$ \\
\hline 17 & 2,100 & NB & Sepsis & $\mathbf{S}$ & II & - & $4.2(60)$ \\
\hline 18 & 3,300 & 10 days & Meningitis & $\mathbf{S}$ & III & $4.0(60)$ & $5.2(60)$ \\
\hline 19 & 2,800 & NB & Sepsis & $\mathbf{S}$ & Ia & - & $4.8(60)$ \\
\hline 20 & - & $22 \mathrm{yr}$ & Puerperal sepsis & $\mathbf{S}$ & II & $5.7(60)$ & $5.9(75)$ \\
\hline 21 & - & 80 yr & Sepsis, meningitis & D & III & $4.1(75)$ & $7.3(75)$ \\
\hline
\end{tabular}

* NB, symptomatic in first $48 \mathrm{~h}$ of life.

I S, survived; D, died.

$(\quad)=$ Time in minutes to peak in CL.

polysaccharide, capsular antigen; $(b)$ Ib and Ic have a shared protein antigen; (c) Ib has a major, capsular polysaccharide antigen; and $(d) \mathrm{Ia}, \mathrm{Ib}$, and Ic have a shared minor polysaccharide antigen which has been termed the Ia, b, c antigen (10). Because of these different antigenic determinants and the cross reactivity between strains, we chose to examine only the Ia strain. The major antigens of the type II and III group B streptococci appear to be capsular polysaccharides without significant cross reactivity. Lancefield and Freimer (18) have indicated that extraction of the group B capsular polysaccharide antigen with TCA yields a more complete antigen containing galactose, glucose, glucosamine, and a labile sialic acid-containing component. Treatment of this TCA extract or whole organisms with hot $\mathrm{HCl}$ yields a

TABLE IV

Group B Streptococcal Opsonins in Serum from Infected and Colonized Patients

\begin{tabular}{|c|c|c|c|c|c|c|}
\hline \multirow[b]{2}{*}{ Patient group } & \multicolumn{3}{|c|}{ Homologous reference strain } & \multicolumn{3}{|c|}{ Strain from patient } \\
\hline & Tested & Opsonins & & Tested & Opsonins & \\
\hline & $n$ & $\%$ & P value* & $n$ & $\%$ & P value* \\
\hline Colonized mothers & 18 & 56 & $<0.005$ & 4 & 50 & $<0.023$ \\
\hline Colonized infants & 9 & 78 & & 4 & 50 & \\
\hline Infected infants & 19 & 16 & & 13 & 0 & \\
\hline Infected adults & 2 & 50 & & 2 & 0 & \\
\hline
\end{tabular}

* Fisher Exact test, comparison of infected patients to colonized patients. 
degraded "partial" capsular antigen. In their studies, absorption of rabbit hyperimmune antiserum with either the $\mathrm{HCl}$ or the TCA extract removed some, but not all, of the mouse protective activity. This suggested the possibility of another antigen-antibody system important in the virulence of these organisms.

In the present studies, absorption of rabbit hyperimmune antiserum with the homologous TCA antigen extract removed all detectable precipitins but only a portion of the opsonic antibody with types Ia and III. Absorption with "partial" $\mathrm{HCl}$ antigen had varying results on the three types. It significantly decreased the opsonic activity of the Ia antiserum, suggesting that this determinant is a major one in strains of this type. Paradoxically, absorption of type II rabbit antiserum with homologous type $\mathrm{HCl}$ and TCA extracts so that all detectable precipitins were removed consistently enhanced opsonization as measured by CL. The reason for this extremely reproducible phenomenon is unknown. One possible explanation is that the unabsorbed type II antiserum caused agglutination of the organisms resulting in fewer individual organisms being available to the PMNs for phagocytosis. The rabbit antiserum to each of the types possessed agglutinins, however, and absorption with the $\mathrm{HCl}$ extracts did not remove this activity. It is conceivable that a prozone phenomena was operative here, but to our knowledge this has not been described in an opsonic antibody system. Another possible explanation is that antibodies directed against the $\mathrm{HCl}$ and TCA determinant of the type II strain compete for the binding site (or a portion of the site) needed for the opsonic antibody.

The failure of complete absorption of opsonic antibody after removal of all detectable precipitins with either the $\mathrm{HCl}$ or the TCA extract may indicate the presence of another antigenic determinant on whole cells of group B streptococci, as has been suggested by Lancefield and Freimer (18). Characterization of this determinant, if it exists, and the antibodies directed against it may be of utmost importance in efforts aimed at developing a vaccine for these organisms.

Of interest is the fact that recently isolated "wild" strains of group B streptococci resist opsonization by antibody and complement more than stock strains of the same type. The reason for this phenomena is unknown, but may be related to the quantity of antiphagocytic factors being produced. We were unable to confirm, however, that manipulations designed to enhance capsular polysaccharide production, such as the use of buffered enriched medium or log phase growth cultures, resulted in a decrease in phagocytic uptake when specific antibody was present.

The role of complement, both classic and alternative pathways, in the opsonization of group B strepto- cocci also needs further study. We were consistently able to significantly enhance opsonization of types I and II strains with whole human complement, but this preparation had no effect on type III organisms. This was true if stock or wild group B streptococcal strains were used. In addition, type Ia strains incubated in fresh human serum demonstrated significant amounts of complement on their surface but did not elicit a peak in CL. This suggests that the alternative pathway may not play a major role in opsonizing these bacteria.

Dossett et al. detected opsonins to group B streptococci in whole blood and serum in 1969 (20). Subsequently Klesius et al. (21) and Mathews et al. (22) reported that serum from humans and experimentally infected baboons contained opsonins directed against types Ia, Ib, Ic, II, and III organisms. Their studies, which were carried out by visually determining phagocytic uptake and the percentage of PMNs ingesting microorganisms, suggested that types Ib, Ic, II, and III streptococci were naturally and nonspecifically opsonized by $95 \%$ of human and baboon sera. Absorption of such serum with homologous type whole organisms did not decrease opsonic activity. In contrast our studies and those of Lancefield and co-workers $(10,18)$ would suggest that opsonic or mouse protective antibody is type specific, since homologous but not heterologous type absorption of serum with whole cells removes this activity. It should be noted, however, that antiserum containing excellent precipitins against the group B group specific carbohydrate does not possess opsonic activity as measured in our system or mouse protective antibody as measured in Dr. Lancefield's procedure.

Recently Baker and Kasper (23) have developed a radioactive antigen-binding assay for detecting antibody directed against a polysaccharide antigen containing both group-specific carbohydrate determinants and the type III capsular polysaccharide of group B streptococci. This test apparently measures all antibodies (precipitin, agglutinin, opsonic, etc.) directed against this combined antigen. Our results and those of Lancefield and co-workers $(10,18)$ would suggest that precipitins or agglutinins directed against the group-specific carbohydrate have no role in protection. In addition, antisera against other types of group B streptococci show cross reactivity with the combined antigen used in the radioimmunoassay. Using this technique, they have found that patients who develop type III group B streptococcal disease (predominantly late onset as vs. early onset in our series) usually lack antibody to the combined type III and group B polysaccharide antigen (23). Although these results are very similar to ours, the radioimmunoassay does not, of course, assess functional opsonic activity.

The most striking finding in the data reported here 
is the absence of opsonins to the infecting organism in 12 of our early onset bacteremic newborns, 1 case of late onset meningitis, and 2 bacteremic adults. A statistical comparison of these data reveal a significant difference between the prevalence of opsonins in colonized patients vs. those who became infected. Clearly, the absence of type-specific opsonic activity appears to be one risk factor in the development of systemic infection.

\section{ACKNOWLEDGMENTS}

We thank Nancy Hogan, Mary Portas, and Gay Kurth for technical assistance and Marcy Pixton for secretarial aid.

This investigation was supported, in part, by U. S. Public Health Service grants AM 18354 and AI-13150.

\section{REFERENCES}

1. Hood, M., A. Janney, and G. Dameron. 1961. Beta hemolytic streptococcus group B associated with problems in the neonatal period. Am.J. Obstet. Gynecol. 82: 809-818.

2. Eickhoff, T. C., J. O. Klein, A. K. Daly, D. Ingall, and M. Finland. 1964. Neonatal sepsis and other infections due to group B beta-hemolytic streptococci. N. Engl. J. Med. 271: 1221-1228.

3. Baker, C. J., F. F. Barrett, R. C. Gordon, and M. D. Yow. 1973. Suppurative meningitis due to streptococci of Lancefield group B: A study of 33 infants. J. Pediatr. 82: 724-729.

4. Franciosi, R. A., J. D. Knostman, and R. A. Zimmerman. 1973. Group B streptococcal neonatal and infant infections. J. Pediatr. 82: 707-718.

5. Baker, C. J., and F. F. Barrett. 1973. Transmission of group B streptococci among parturient women and their neonates. J. Pediatr. 83: 919-925.

6. Howard, J. B., and G. H. McCracken, Jr. 1974. The spectrum of group B streptococcal infections in infancy. Am. J. Dis. Child. 128: 815-818.

7. Wilkinson, H. W., R. R. Facklam, and E. C. Wortham. 1973. Distribution by serological type of group B streptococci isolated from a variety of clinical material over a five-year period with special reference to neonatal sepsis and meningitis. Infect. Immun. 8: 228-235.

8. Hemming, V. G., D. W. McCloskey, and H. R. Hill. 1976. Pneumonia in the neonate associated with group $B$ streptococcal septicemia. Am. J. Dis. Child. In press.

9. Lancefield, R. C. 1934. A serological differentiation of specific types of bovine hemolytic streptococci (group B). J. Exp. Med. 59: 441-458.

10. Lancefield, R. C., M. McCarty, and W. N. Everly. 1975.
Multiple mouse-protective antibodies directed against group B streptococci. J. Exp. Med. 142: 165-179.

11. Allen, R. C., R. L. Stjernholm, and R. H. Steele. 1972. Evidence for the generation of an electronic excitation state $(s)$ in human polymorphonuclear leukocytes and its participation in bactericidal activity. Biochem. Biophys. Res. Commun. 47: 679-684.

12. Stjernholm, R. L., R. C. Allen, R. H. Steele, W. W. Waring, and J. A. Harris. 1973. Impaired chemiluminescence during phagocytosis of opsonized bacteria. Infect. Immun. 7: 313-314.

13. Allen, R. C. 1975. Halide dependence of the myeloperoxidase mediated antimicrobial system of the polymorphonuclear leukocyte in the phenomenon of electronic excitation. Biochem. Biophys. Res. Commun. 63: 675683.

14. Allen, R. C. 1975. The role of $\mathrm{pH}$ in the chemiluminescent response of the myeloperoxidase-halideHOOH antimicrobial system. Biochem. Biophys. Res. Commun. 63: 684-691.

15. Allen, R. C., S. J. Yevich, R. W. Orth, and R. H Steele. 1974. The superoxide anion and singlet molecular oxygen: their role in the microbiocidal activity of the polymorphonuclear leukocyte. Biochem. Biophys. Res. Commun. 60: 909-917.

16. Baker, C. J., and D. L. Kasper. 1976. Microcapsule of type III strains of group B streptococcus: production and morphology. Infect. Immun. 13: 189-194.

17. Lancefield, R. C. 1938. A micro-precipitin-technique for classifying hemolytic streptococci and improved methods for producing antisera. Proc. Soc. Exp. Biol. Med. 38: 473-478.

18. Lancefield, R. C., and E. H. Freimer. 1966. Typespecific polysaccharide antigens of group B streptococci. J. Hyg. 64: 191-203.

19. Hill, H. R., M. E. Riter, S. K. Menge, D. R. Johnson, and J. M. Matsen. 1975. Rapid identification of group B streptococci by counter-immunoelectrophoresis. J. Clin. Microbiol. 1: 188-191.

20. Dossett, J. H., R. C. Williams, Jr., and P. G. Quie. 1969. Studies on the interaction of bacteria, serum factors and polymorphonuclear leukocytes in mothers and newborns. Pediatrics. 44: 49-57.

21. Klesius, P. H., R. A. Zimmerman, J. H. Mathews, and C. H. Krushak. 1973. Cellular and humoral immune response to group B streptococci. J. Pediatr. 83: 926-932.

22. Mathews, J. H., P. H. Klesius, and R. A. Zimmerman. 1974. Opsonin system of the group B streptococcus. Infect. Immun. 10: 1315-1320.

23. Baker, C. J., and D. L. Kasper. 1976. Correlation of maternal antibody deficiency with susceptibility to neonatal group B streptococcal infection. N. Engl. J. Med. 294: 753-756. 